Journal for ImmunoTherapy of Cancer

\title{
CD47/SIRPa blocking peptide identification and synergistic effect with irradiation for cancer immunotherapy
}

\author{
Hongfei Wang, ${ }^{1}$ Yixuan Sun, ${ }^{1}$ Xiuman Zhou (D) , ${ }^{1}$ Chunxia Chen, ${ }^{1}$ Ling Jiao, ${ }^{1}$ \\ Wanqiong $\mathrm{Li}^{2}{ }^{2}$ Shanshan Gou, ${ }^{1}$ Yanying $\mathrm{Li},{ }^{1}$ Jiangfeng Du, ${ }^{1}$ Guanyu Chen, ${ }^{2}$ \\ Wenjie Zhai, ${ }^{1}$ Yahong Wu, ${ }^{1}$ Yuanming Qi, ${ }^{1}$ Yanfeng Gao (D) ${ }^{2}$
}

To cite: Wang H, Sun Y, Zhou X, et al. CD47/SIRP $\alpha$ blocking peptide identification and synergistic effect with irradiation for cancer immunotherapy. Journal for ImmunoTherapy of Cancer 2020;8:e000905. doi:10.1136/jitc-2020-000905

- Additional material is published online only. To view please visit the journal online (http://dx.doi.org/10.1136/jitc2020-000905).

Accepted 03 September 2020

Check for updates

(C) Author(s) (or their employer(s)) 2020. Re-use permitted under CC BY. Published by BMJ.

${ }^{1}$ School of Life Sciences, Zhengzhou University,

Zhengzhou, Henan, China

${ }^{2}$ School of Pharmaceutical

Sciences (Shenzhen), Sun

Yat-sen University, Shenzhen, Guangdong, China

Correspondence to Professor Yanfeng Gao; gaoyf29@mail.sysu.edu.cn

\section{ABSTRACT}

Background Immunotherapy has achieved remarkable advances via a variety of strategies against tumor cells that evade immune surveillance. As important innate immune cells, macrophages play important roles in maintaining homeostasis, preventing pathogen invasion, resisting tumor cells and promoting adaptive immune response. CD47 is found to be overexpressed on tumor cells and act as a don't eat me' signal, which contributes to immune evasion. Macrophages mediated phagocytosis via blockade CD47/SIRP $\alpha$ (signal regulatory protein alpha) interaction was proved to induce effective antitumor immune response.

Methods A novel peptide pep-20, specifically targeting CD47 and blocking CD47/SIRP $\alpha$ interaction, was identified via high-throughput phage display library bio-panning. The capability to enhance the macrophage-mediated phagocytosis activities and antitumor effects of pep20 were investigated. The mechanism of pep-20 to induce T-cell response was explored by ex vivo analysis and confirmed via macrophage depleting strategy. The structure-activity relationship and D-amino acid substitution of pep-20 were also studied. The antitumor effects and mechanism of a proteolysis resistant D-amino acid derivate pep-20-D12 combined with irradiation (IR) were also investigated.

Results Pep-20 showed remarkable enhancement of macrophage-mediated phagocytosis to both solid and hematologic tumor cells in vitro, and inhibited tumor growth in immune-competent tumor-bearing mice. Furthermore, pep-20 promoted macrophages to mobilize the antitumor T-cell response with minimal toxicity. Furthermore, systemic administration of the derivate pep20-D12 showed robust synergistic antitumor efficacy in combination with IR.

Conclusion In summary, these results demonstrated that CD47/SIRP $\alpha$ blocking peptides, pep-20 and its derivate, could serve as promising candidates to promote macrophages-mediated phagocytosis and immune response in cancer immunotherapy.

\section{BACKGROUND}

As one of the most important components of innate immune, macrophages play key roles in recognizing and removing foreign, aged, damaged and dying cells from tissues and maintaining tissue homeostasis. Besides, macrophages can prevent the invasion of exogenous pathogens and eliminate endogenous pathogens to promote adaptive immune response. ${ }^{1}$ Macrophages-mediated phagocytosis is modulated via the balance of prophagocytosis and anti-phagocytosis signals, which expose on the surface of objective cells under normal physiological conditions. For example, macrophages can recognize specific 'eat me' signals, including phosphatidylserine, intercellular adhesion molecule 3 and calreticulin on the dying cells distinguished from the nearby normal cells via respective engulfment receptors. Subsequently, these dying cells are uptaken by macrophages. Conversely, tumor cells express the 'don't eat me' signals on the surface to suppress phagocytosis. ${ }^{2} 3$ Therefore, it is urgent to develop appropriate therapeutic agents to block the anti-phagocytosis signals and improve the antitumor therapeutic efficacy.

CD47 is well known to act as a 'don't eat me' signal, interact with SIRP $\alpha$ on macrophages to deliver negative regulatory signals, and thus prevent phagocytic removal of the cells by the immune system. ${ }^{4}$ Previous studies have shown that upregulation of CD47 on hematopoietic stem cells and progenitor cells could act as a self-protective strategy against phagocytosis to avoid additional clearance during inflammation-mediated migration phase. ${ }^{5}$ CD47 might serve as a "marker of self' on red blood cells, as CD47-deficient hematopoietic cells can be rapidly cleared from the bloodstream. ${ }^{67}$ Frustratingly, many studies have shown that overexpression of CD47 could be detected in many types of solid tumors and hematologic malignancies, including cancer stem cells. ${ }^{8}$ Tumor cells can upregulate $\mathrm{CD} 47$ as the 'don't eat me' signal, which in turn prevents themselves 
from being recognized and cleared by macrophages to escape immune surveillance. Fortunately, more studies have confirmed that $\mathrm{CD} 47$ blockade could reactivate the phagocytic efficacy of macrophages, and various strategies have been established for disrupting the CD47/ SIRP $\alpha$ interaction. Among them, anti-CD47 antibodies can trigger macrophages-mediated phagocytosis and exhibit greater antitumor therapeutic efficacy against solid tumors or hematological malignancies. Moreover, SIRP $\alpha$ mutants 'CV1' and CD47 mutants 'Velcro-CD47' with high affinities have been reported to be adjuvants to augment the efficacy of therapeutic antibodies. ${ }^{9} 10$ For example, anti-human CD47 antibody (B6H12) can markedly suppress tumor growth in ovarian, breast, colon cancer, glioblastoma and acute lymphoblastic leukemia in NOD-scid Il2ry null mice xenotransplantation models. ${ }^{11}$ Also, anti-CD47 antibody can synergize with rituximab (anti-CD20) to promote phagocytosis of macrophages and eliminate non-Hodgkin's lymphoma. ${ }^{12}$ Furthermore, several studies suggested that blockade of CD47/SIRP $\alpha$ interaction could further activate the function of adaptive immune response towards cancer that is particularly mediated by cytotoxic $\mathrm{T}$ lymphocytes in immunocompetent mouse models. ${ }^{13} 14$ Anti-mouse CD47 antibody therapeutic efficacy can be impaired by depletion of $\mathrm{CD} 8^{+} \mathrm{T}$ cells, and the induced memory T-cell mediated response can completely resist tumor cells re-challenge. ${ }^{15}$ These findings confirmed that $\mathrm{CD} 47$ blockade have emerged as a promising strategy for cancer immunotherapy.

To date, agents targeting the CD47/SIRP $\alpha$ axis include antibodies and recombinant mutant fusion proteins which have been performed in preclinical studies and clinical trials, either as monotherapy or in combination with other therapeutics. These clinical trials were conducted for various indications in several solid tumors or hematological malignancies. However, the potent receptor occupation of these agents led to the potential side effects, such as anemia. ${ }^{16}$ Therefore, it is very urgent to develop CD47 blocking therapeutics which could reduce the potential side effects and maintain a good balance between safety and efficacy.

Peptides can retain the advantages of antibodies, which also have other merits such as lower immunogenicity, greater tissue penetration owing to their smaller size and minimize the risks of systemic toxicity. Moreover, peptides are easier to synthesize and can be modified by artificial methods with low cost. Peptide drugs have shown specific advantages and wide application prospects in inducing tumor cell apoptosis, inhibiting angiogenesis and being used as vaccines or drug carriers. ${ }^{1718}$ The crystal structure of CD $47 /$ SIRP $\alpha$ indicated that receptor-ligand interactions occurred via the connection of amino acid residues of adjacent peptide segments. The screening strategy of phage-display library has been widely used to identify specific peptides which are capable of binding to corresponding targets, including enzymes, hormones, receptors or tissues. ${ }^{19} 20$ However, peptides targeting CD47 to block CD47/SIRP $\alpha$ interaction for cancer immunotherapy still remain to be investigated.

In this study, a subtractive phage bio-panning strategy was applied to identify peptides that possessed the specificity of binding to human CD47 and blocking the CD47/ SIRP $\alpha$ interaction. The antitumor therapeutic effects and mechanism of the peptide candidates were investigated, as well as combination of the D-amino acid-modified peptide derivate with irradiation (IR).

\section{METHODS}

\section{Binding assays}

Human or mouse CD47-IgV-Domain proteins were labeled with NT-647 dye following the microscale thermophoresis (MST) assay protocol, and the labeled protein used for each assay was about 50 to $200 \mathrm{nM}$. Unlabeled peptides or ligand protein solution was diluted for appropriate concentration serially in buffer $(50 \mathrm{mM}$ Tris, 150 $\mathrm{mM} \mathrm{NaCl}, 10 \mathrm{mM} \mathrm{MgCl}, 0.05 \%$ Tween-20, 0.5\% DMSO and $\mathrm{pH}$ 7.5). The labeled proteins were then added to peptides or ligand protein solutions by $1: 1(\mathrm{v} / \mathrm{v})$. The samples were loaded into silica capillaries after incubation at room temperature for $30 \mathrm{~min}$. Binding constants were determined by the MST assay according to manufacturer's instructions with $20 \%$ or $40 \%$ light emitting diode (LED) power, $40 \%$ MST power at $25^{\circ} \mathrm{C}$ (Nano Temper, Monolith NT.115, Germany). Data analysis were performed by using a Nanotemper Analysis software.

\section{Blocking assays}

Human or mouse CD47-IgV-Domain-hIg fusion proteins (20 nM, Sino Biological, China), or biotinylated human CD47 protein (20 nM, ACROBiosystems, USA) was incubated with titrating concentrations of peptides or antihuman CD47 antibody (B6H12) in phosphate-buffered saline (PBS, pH 7.4) for 1 hour at $4^{\circ} \mathrm{C}$. The mixture was incubated with human or mice SIRP $\alpha$ overexpressed Chinese hamster ovary cells for $30 \mathrm{~min}$ at $4^{\circ} \mathrm{C}$, washed to remove unbound mixtures and phycoerythrin (PE)conjugated goat anti-human IgG or PE-conjugated streptavidin was incubated (eBioscience, USA). Cells were then analyzed by flow cytometry (BD Biosciences, USA). The $\mathrm{IC}_{50}$ was determined from sigmoidal dose response curves illustrated by GraphPad Prism.

\section{Phagocytosis assays in vitro}

Murine bone marrow cells were isolated from 7 to 11 weeks old C57BL/6 or BALB/c mice. Human peripheral blood mononuclear cells were collected from venous blood of healthy volunteers, diluted with $2 \times \mathrm{PBS}(\mathrm{pH}$ 7.4) and separated with Ficoll density gradient. The cells were cultured in DMEM (GIBCO, USA) supplemented with $10 \%$ fetal bovine serum and $20 \mathrm{ng} / \mathrm{mL}$ granulocyte macrophage colony-stimulating factor (GM-CSF) or macrophage colony-stimulating factor (M-CSF, Peprotech, USA) for 7 days. Meanwhile, medium was replaced with fresh medium containing cytokine, and then the 
adherent cells were harvested. Phagocytosis assays were performed by co-culture of macrophages with carboxyfluorescein succinimidyl ester $\left(\mathrm{CFSE}^{+}\right)$or green fluorescent protein $\left(\mathrm{GFP}^{+}\right)$tumor cells at a 1:4 ratio in serum-free medium at $37^{\circ} \mathrm{C}$ for 4 hours in low-attachment 96-well tissue culture plates (Corning, USA). The cells were harvested, and primary macrophages were identified by flow cytometry using anti-F4/80 or anti-CD14 antibody (eBioscience, USA). Then, 7-AAD (eBioscience, USA) was added to exclude dead cells in some experiments. Phagocytosis rate was determined as the percentage of $\mathrm{CFSE}^{+}$or $\mathrm{GFP}^{+}$macrophages.

\section{Tumor models and treatments}

C57BL/6 mice were subcutaneously (s.c.) injected with $1 \times 10^{6}$ MC38 cells or $2 \times 10^{5}$ B16-OVA into the flank, and $\mathrm{BALB} / \mathrm{c}$ mice were s.c. injected with $2 \times 10^{5} \mathrm{CT} 26$ cells into the flank. Tumor volumes were measured every other day by length (a), width (b) and height (c), and calculated as tumor volume $=\mathrm{abc} / 2$. Tumors were grown for approximately a week, the mice were then injected s.c. with $2 \mathrm{mg} /$ $\mathrm{kg}$ pep-20 or normal saline as the negative control at the peritumoral site every day. Treatment was continued for 2 weeks, then the mice were euthanized, tumors, spleens and draining lymph nodes were dissected. For macrophages depletion, $\mathrm{C} 57 \mathrm{BL} / 6$ mice were intraperitoneally (i.p.) injected with $150 \mu \mathrm{L}$ clodronate liposome or control liposome (FormuMax Scientific, USA) on day 6, and every 4 days after injection of $1 \times 10^{6}$ MC38 cells until finishing the experiment. The efficiency of macrophages depletion was determined by flow cytometry analysis of the CD $45^{+}$ $\mathrm{CD}_{11} \mathrm{~b}^{+} \mathrm{F} 4 / 80^{+}$cells. For pep-20-D12 treatment, $1 \times 10^{6}$ MC38 cells were injected s.c. into the flank of mice, and 2 $\mathrm{mg} / \mathrm{kg}$ pep-20-D12 every day or $400 \mu \mathrm{g}$ anti-mouse CD47 antibody (miap301, Bio-XCell, USA) every 3 days for a total of five times as the positive control was injected i.p. into the mice, with normal saline and ratIg as the negative controls. For radiotherapy (RT), $1 \times 10^{6}$ MC38 cells were injected s.c. into the flanks of mice, tumors were allowed to grow to reach 80 to $100 \mathrm{~mm}^{3}$ before being treated with RT. Tumors locally received one $20 \mathrm{~Gy}$ dose IR and then $2 \mathrm{mg} / \mathrm{kg}$ pep-20-D12 was injected i.p. into the mice every day for 2 weeks.

For $\mathrm{CD} 8^{+} \mathrm{T}$ cells detection in tumors, single cell suspensions from tumor tissues were prepared by gentle mechanical disruption, the tumor masses were then digested with collagenase IV (Invitrogen, USA) and Dnase I (Sigma, USA) for $30 \mathrm{~min}$ at $37^{\circ} \mathrm{C}$, and cells were passed through a $70 \mu \mathrm{m}$ nylon cell strainer. Tumor cells were stained with anti-mouse CD45, anti-mouse CD3, anti-mouse CD8 $\alpha$ or isotype control, and then analyzed by flow cytometry.

For intracellular cytokine staining assay, tumorinfiltrating lymphocytes (TILs) were purified using Ficollgradient centrifugation (GE, USA). Single cell suspensions from TILs, draining lymph nodes or spleens were re-stimulated with $20 \mathrm{ng} / \mathrm{mL}$ phorbol 12-myristate 13-acetate (PMA, Sigma, USA) and $1 \mu \mathrm{M}$ ionomycin (Sigma, USA) for 4 hours to CT26 and MC38 tumor-bearing mice, or
$10 \mu \mathrm{g} / \mathrm{mL} \mathrm{OVA}_{257-264}$ peptide for 6 hours to B16-OVA tumor-bearing mice, in the presence of protein transport inhibitor cocktail (eBioscience, USA). Interferon (IFN)- $\gamma$ production from $\mathrm{CD} 8^{+} \mathrm{T}$ cells was detected with antimouse CD3, anti-mouse CD $8 \alpha$, and anti-mouse IFN- $\gamma$ or isotype control, and then analyzed by flow cytometry.

For ELISA assay, spleen or draining lymph node cells were re-stimulated with $0.5 \mu \mathrm{g} / \mathrm{mL}$ anti-CD3 and $0.5 \mu \mathrm{g} /$ $\mathrm{mL}$ anti-CD28 antibodies (eBioscience, USA) for 3 days to CT26 and MC38 tumor-bearing mice, or $10 \mu \mathrm{g} / \mathrm{mL}$ $\mathrm{OVA}_{25-264}$ peptide for 5 days to B16-OVA tumor-bearing mice. Cellular supernatant IFN- $\gamma$ secretion was measured by using an ELISA kit (eBioscience, USA).

\section{Statistical analysis}

Statistical analysis were performed with unpaired Student's t-test for analyzing differences between groups. The Kaplan-Meier curve and the log-rank test were used for analyzing overall survival rate of the mice. Data were represented as means \pm SEM unless otherwise indicated. $* \mathrm{p}<0.05, * * \mathrm{p}<0.01$ and $* * * \mathrm{p}<0.001$ were considered statistically significant.

\section{RESULTS}

\section{CD47 is significantly overexpressed in tumors}

The CD47 expression in different tumor tissues from The Cancer Genome Atlas (TCGA) and GenotypeTissue Expression (GTEx) data sets was evaluated. It was found that CD47 expression was markedly higher in various kinds of tumor tissues compared with normal counterparts (online supplemental figure S1A). Consistently, CD47 was expressed at high levels on various solid and hematologic tumor cell lines shown by flow cytometry analysis (online supplemental figure S1B). As previous studies have shown, ${ }^{21}$ the high expression of CD47 in tumors suggested the potential of targeting CD47 for antitumor immunotherapy.

\section{Bio-panning and identification of peptides binding CD47 via phage display strategy}

To identify the peptides binding to human CD47, the solution-phase biopanning was performed with affinity beads capture strategy, which improved accessibility of the protein-binding site according to the standard protocol of the Ph.D.-12 phage display peptide library using human CD47-IgV-Domain protein as the target. ${ }^{22}$ Phages that are not specifically binding with CD47 can be avoided by employing a negative selection strategy. After five rounds of bio-panning, phages of enrichment were obtained and phage plaques were randomly selected for DNA sequencing. Subsequently, the sequences were aligned using Clustal Omega, ${ }^{23}$ and several consensus sequences were apparently different, such as 'YKEHYLY' and 'TXSNY' (online supplemental figure S2). This indicated that the binding regions of these phages to CD47 might not be the same cluster. Therefore, in order to reduce the 'off-rate', peptides 
with different common sequences were accepted. Based on the selection strategy, 12 candidate peptides were further screened to identify which could bind to human CD47 (online supplemental table S1).

\section{Pep-20 binds to CD47 and blocks the CD47/SIRP $\alpha$ interaction}

To assess the affinity of these candidate peptides toward human $\mathrm{CD} 47$, the preliminary binding assay was performed. Several peptides were confirmed to bind human CD47 with a relatively strong affinity comparable to the native $\mathrm{CD} 47 / \mathrm{SIRP} \alpha$ interaction, such as pep-3 and pep-20. In addition, due to the presence of consensus sequences, it can be hypothesized that the peptides pep-5, pep-9 and pep-19 may have higher affinities. But due to the poor solubility, it's not available to use the higher titrating concentrations to determine the saturation binding concentration (online supplemental table S1). Subsequently, pep-20 was examined to bind to human and mouse $\mathrm{CD} 47$ with the $\mathrm{K}_{\mathrm{D}}$ values of $2.91 \pm 1.04$ $\mu \mathrm{M}$ and $3.63 \pm 1.71 \mu \mathrm{M}$, respectively (figure $1 \mathrm{~A}, \mathrm{~B}$ ).

To evaluate the ability of the peptide candidates to block the CD47/SIRP $\alpha$ interaction, the blocking assay was performed in vitro. Three peptides (pep-15, pep-16 and pep-20) could block the interaction of $\mathrm{CD} 47$ / SIRP $\alpha$ (online supplemental figure S3), among which pep-20 exhibited the greatest dose-dependent effect with an $\mathrm{IC}_{50}$ of $24.56 \mu \mathrm{M}$ (figure $1 \mathrm{C}$ ). The anti-CD47 antibody (B6H12) served as a positive control with an $\mathrm{IC}_{50}$ of $6.94 \mu \mathrm{g} / \mathrm{mL}$ (online supplemental figure $\mathrm{S} 4$ ). The same experiment was also performed in a mouse blocking system, and the blockade of pep-20 to mouse $\mathrm{CD} 47 / \mathrm{SIRP} \alpha$ interaction was determined with an $\mathrm{IC}_{50}$ of $12.03 \mu \mathrm{M}$ approximately (figure 1D). These results clearly demonstrated that pep-20 could bind to CD47 and block the interaction of CD47/SIRP $\alpha$.

\section{Pep-20 enhances macrophages-mediated phagocytosis of tumor cells}

Previous studies showed that phagocytosis of macrophages was the major mechanism of CD47 targeted therapies. ${ }^{8}$ Thus, the in vitro capability of pep-20 to facilitate macrophages-mediated phagocytosis of tumor cells was investigated. Three different human tumor cell lines of MCF7, HT29 and Jurkat were offered to macrophages as target cells, and the results showed that pep-20 significantly increased macrophages-mediated phagocytosis of tumor cells, which was slightly inferior to the anti-CD47 antibody (B6H12) positive control (figure $1 \mathrm{E}-\mathrm{G}$ ). Subsequently, whether the mouse macrophages possessed efficacy of phagocytosis towards murine tumor cells in the presence of pep-20 was also investigated. As a result, similar phagocytosis occurrences were observed from CT26, MC38 and B16OVA tumor cells treated with pep-20 (figure $1 \mathrm{H}-\mathrm{J}$ ). To confirm the specificity of pep-20 targeting CD47, the CD47 knockdown HT29 and MC38 tumor cells were established. CD47 knockdown impairs the efficacy of pep-20 to induce macrophage-mediated phagocytosis of tumor cells (online supplemental figure S5). These results demonstrated that pep-20 might have potential therapeutic activity in tumor-bearing mice.

\section{Pep-20 reduces the tyrosine phosphorylation of SIRP $\alpha$ via CD47 engagement}

To further verify the ability of pep-20 to block CD47/ SIRP $\alpha$ interaction, the SIRP $\alpha$ tyrosine residues phosphorylation with pep-20 intervention was evaluated. ${ }^{24}$ As a negative regulation signal of CD47/SIRP $\alpha$ axis, the ligation of SIRP $\alpha$ by CD47 could lead to tyrosine phosphorylation of immunoreceptor tyrosine-based inhibitory motifs (ITIMs) in its cytoplasmic domain. ${ }^{25}$ For the validity of the experimental results, SIRP $\alpha$ expression on several murine tumor cells was evaluated and it was found that SIRP $\alpha$ was not detected on CT26 cells. Following incubation of mouse bone marrow-derived macrophages with CT26 cells, it was found that pep-20 could reduce the tyrosine residues phosphorylation of SIRP $\alpha$, which was consistent with that of anti-CD47 antibody (miap301) (online supplemental figure S6). The results clearly demonstrated that pep-20 could directly block the CD47/SIRP $\alpha$ interaction.

\section{Pep-20 inhibits tumor growth and activates antitumor T-cell immune response}

The antitumor efficacy of pep-20 in tumor-bearing mice was subsequently investigated. MC38 cells were engrafted s.c. on the flank of mice. Tumor growth was significantly suppressed by pep-20 treatment ( $2 \mathrm{mg}$ / $\mathrm{kg}$ ), and mice displayed prolonged overall survival compared with the negative control of normal saline (figure 2A,B). To confirm these results, the antitumor efficacy of pep-20 was also evaluated using similar treatment program in CT26 tumor-bearing mice. The delay of tumor growth and prolonged overall survival were also observed (online supplemental figure S7A,B).

To determine whether pep-20 treatment engages antitumor immune response, the cells from the tumor tissues, tumor-draining lymph nodes and spleen were obtained after treatment. CD47 blockade with pep-20 remarkably increased the intratumoral $\mathrm{CD}^{+} \mathrm{T}$ cell population (figure 2C). In addition, IFN- $\gamma$ expressing $\mathrm{CD}^{+} \mathrm{T}$ cells from tumor-draining lymph nodes and spleen were significantly increased in pep-20 treated MC38 tumor-bearing mice (figure 2D-G). These results were also confirmed in CT26 model (online supplemental figure S7C-G).

Based on these results, we wondered whether pep-20 could enhance tumor antigen specific T-cell immune response. To verify this hypothesis, B16-OVA tumorbearing mice was established. Consistently, pep-20 treatment could significantly suppress tumor growth (figure 3A). The cells from the tumor-draining lymph nodes and spleen were stimulated with $\mathrm{OVA}_{257-264}$ peptide ex vivo after treatment. Pep-20 significantly increased the $\mathrm{CD} 8^{+} \mathrm{T}$ cell population in tumor tissue (figure $3 \mathrm{~B}$ ). Identically, IFN- $\gamma$ expressing $\mathrm{CD}^{+} \mathrm{T}$ cells (stimulated by antigenic peptide $\mathrm{OVA}_{257-264}$ ) in major peripheral 
A.

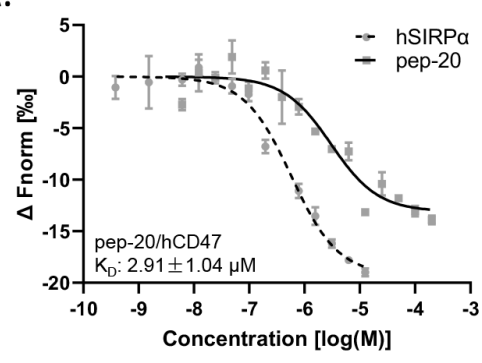

C.

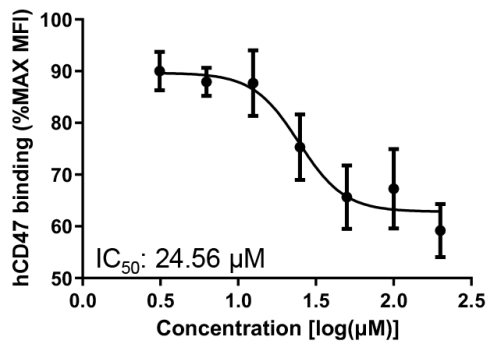

B.

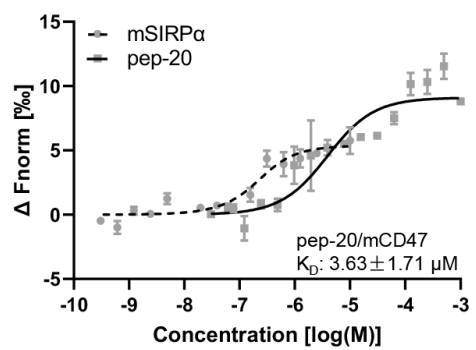

D.

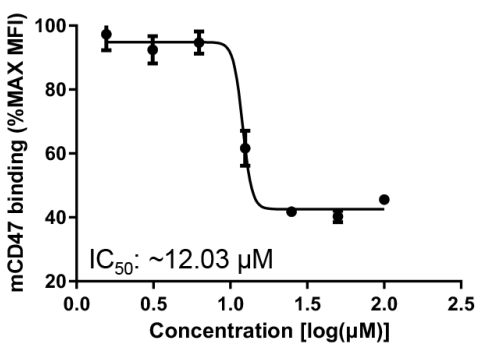

E.

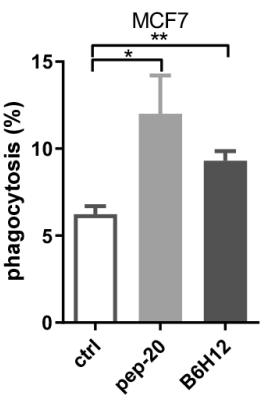

$\mathrm{H}$.

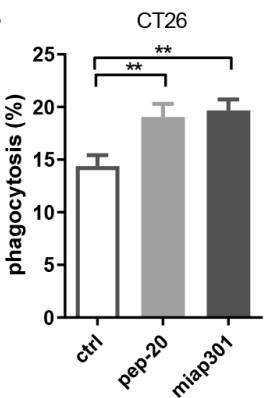

F.

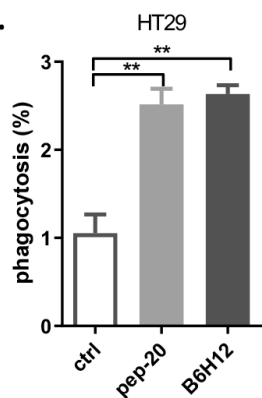

I.

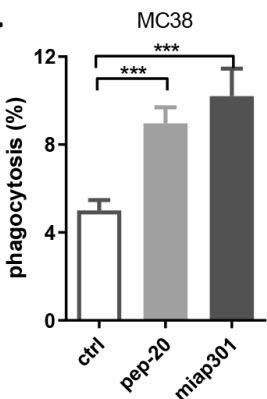

G.

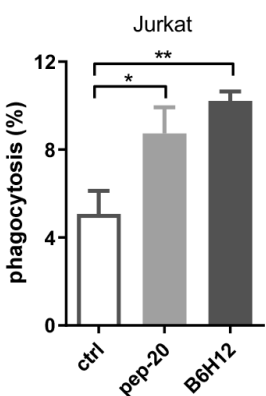

J.

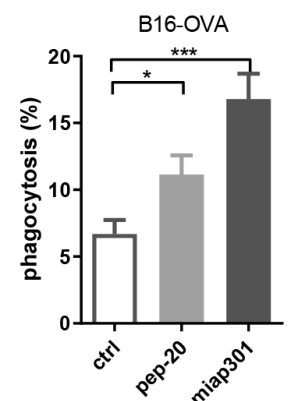

Figure 1 Pep-20 binds to CD47 and blocks the CD47/SIRP $\alpha$ interaction. (A, B) Dose response curves of pep-20 binding to CD47. Binding assay of pep-20 to human (A) or mouse (B) CD47-IgV-Domain protein was examined by the MST. The human or mouse SIRP $\alpha$ protein served as positive control. (C, D) Dose response curves of pep-20 interfering CD47/SIRP $\alpha$ interaction. Flow cytometry analysis of human (C) or mouse (D) CD47-IgV-Domain-hlg fusion protein binding to $\mathrm{CHO}$ stably expressing human or mouse SIRP $\alpha$ cells in the presence of pep-20 with varying gradient concentrations. The data represented as the mean fluorescence intensity normalized to the maximum binding. ( $E$ to $\mathrm{J}$ ) Phagocytosis assays were performed by co-culture of tumor cells with corresponding macrophages at a $1: 4$ ratio in serum-free medium at $37^{\circ} \mathrm{C}$ for 4 hours in low-attachment 96 well plates. GFP ${ }^{+}$MCF7 cells (E), GFP ${ }^{+}$HT29 cells $(F)$ and GFP $^{+}$Jurkat cells $(G)$ were incubated with human peripheral bloodderived macrophages in the presence of $100 \mu \mathrm{M}$ pep- 20 or $20 \mu \mathrm{g} / \mathrm{mL}$ anti-human CD47 antibody (B6H12). CFSE ${ }^{+}$CT26 cells $(\mathrm{H}), \mathrm{GFP}^{+} \mathrm{MC} 38$ cells (I) and GFP ${ }^{+}$B16-OVA cells $(\mathrm{J})$ were incubated with mouse bone marrow-derived macrophages in the presence of $100 \mu \mathrm{M}$ pep-20 or $20 \mu \mathrm{g} / \mathrm{mL}$ anti-mouse CD47 antibody (miap301). Phosphate-buffered saline was negative control in all assays. $\mathrm{CFSE}^{+}$or $\mathrm{GFP}^{+}$macrophages were detected by flow cytometry. Data are represented as means \pm SEM. Statistical significance was determined by unpaired Student's t-test. ${ }^{*} p<0.05 ;{ }^{* *} p<0.01 ;{ }^{* \star *} p<0.001$. CHO, Chinese hamster ovary; CSFE,carboxyfluorescein succinimidyl ester; GFP, green fluorescent protein; MST, microscale thermophoresis.

lymphoid organ from tumor-bearing mice were also increased after pep-20 treatment, especially in draining lymph nodes (figure 3C-F). Collectively, these results demonstrated that blockade of CD47 with pep-20 could delay the tumor growth and induce antigen-specific T-cell immune response. 


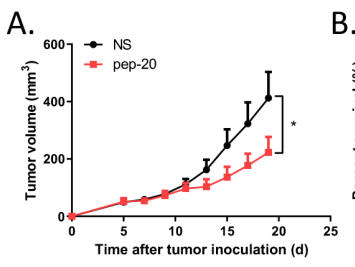

B.
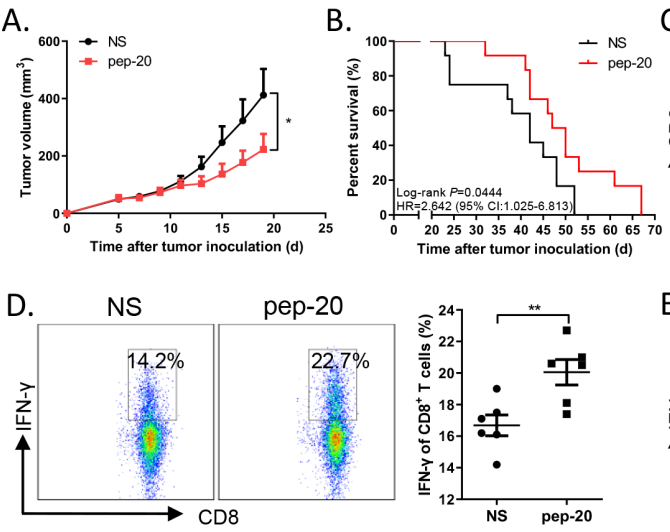

C. NS pep-20
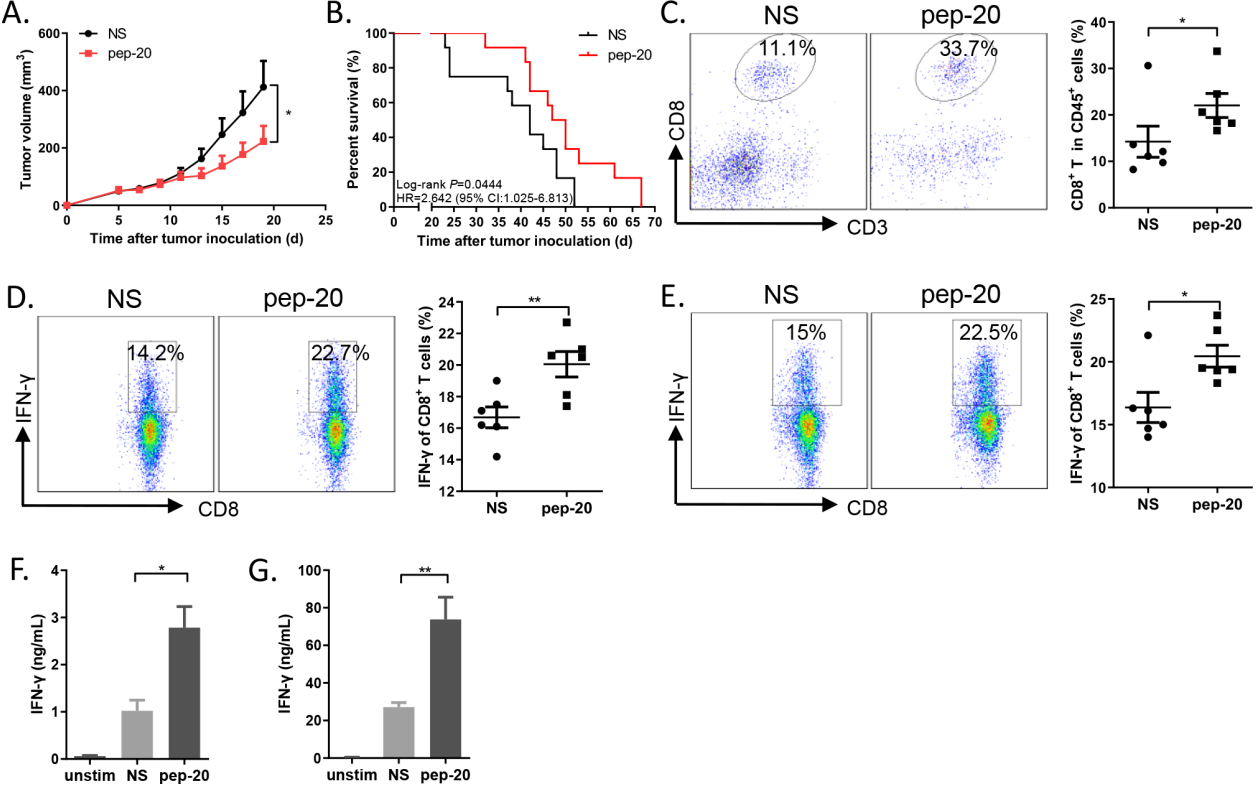

Figure 2 Pep-20 inhibits tumor growth and activates antitumor T-cell immune response in MC38 tumor-bearing mice. C57BL/6 mice were transplanted with $1 \times 10^{6} \mathrm{MC} 38$ cells on the right flank, until the tumor volume reached $50 \mathrm{~mm}^{3}$. (A) Mice were treated s.c. with $2 \mathrm{mg} / \mathrm{kg}$ of pep-20 or normal saline as the negative control at the peritumoral site every day for 2 weeks $(n=8)$. (B) Mice were treated with $2 \mathrm{mg} / \mathrm{kg}$ of pep-20 for 4 weeks and overall survival was monitored $(n=12)$. (C) Tumors were detected for the percentage of tumor-infiltrating $C D 8^{+}$T cells in total $C D 45^{+}$cells $(n=6)$. (D, E) Cells from draining lymph nodes (D) or spleen (E) were obtained and stimulated with $20 \mathrm{ng} / \mathrm{mL}$ of PMA and $1 \mu \mathrm{M}$ ionomycin-containing protein transport inhibitor cocktail for 4 hours. Frequencies of IFN- $\gamma$ expressing $C D 8^{+} T$ cells were detected by flow cytometry $(n=6)$. (F, G) Draining lymph nodes $(F)$ and spleen (G) were obtained and stimulated with $0.5 \mu \mathrm{g} / \mathrm{mL}$ of anti-CD3 and $0.5 \mu \mathrm{g} / \mathrm{mL}$ of anti-CD28 antibodies for 3 days. Cellular supernatant from draining lymph nodes or spleen for IFN- $\gamma$ secretion was measured with ELISA assay ( $n=4$ to 5). Data are represented as means \pm SEM. Statistical significance was determined by unpaired Student's t-test. ${ }^{*} p<0.05 ;{ }^{* \star} p<0.01$. KaplanMeier survival curves were evaluated by log-rank analysis. IFN, interferon; PMA, phorbol 12-myristate 13-acetate.

\section{Pep-20 enhances the activity of $\mathrm{CD}^{+} \mathrm{T}$ cells via macrophages}

Based on the results described above, it can be presumed that macrophages could mobilize the T-cell response after phagocytosis of tumor cells by pep-20. To further verify the effects of pep-20-mediated phagocytosis by macrophages to $\mathrm{CD}^{+}$T-cell response, the proliferation of OT-I T cells was evaluated in vitro. As predicted, macrophages could significantly enhance the activity of $\mathrm{CD} 8^{+}$ $\mathrm{T}$ cells after engulfing B16-OVA cells in the presence of pep-20, which was consistent with the anti-CD47 antibody (miap301) (online supplemental figure S8A,B). In addition, more secretion of IFN- $\gamma$ from $\mathrm{CD}^{+} \mathrm{T}$ cells in the culture supernatants was detected in pep-20-treated group (online supplemental figure $\mathrm{S} 8 \mathrm{C}$ ). These results demonstrated that the phagocytosis of macrophages enhanced by pep- 20 was able to stimulate antitumor $\mathrm{CD} 8^{+}$ T-cell immune response.

\section{Depletion of macrophages impairs the antitumor efficacy of pep-20 in vivo}

To further demonstrate whether macrophages directly contribute to the antitumor effects of pep-20, macrophages were depleted with clodronate liposome before injection of pep-20 in MC38 tumor-bearing mice. ${ }^{26}$ Prior to the experiment, the macrophages were confirmed to be removed effectively in peripheral blood and spleen compared with control liposome (online supplemental figure S9). The detailed description of the treatment program is presented in figure $4 \mathrm{~A}$. By monitoring tumor sizes of MC38-bearing mice, no obvious difference was observed between pep-20 and normal saline groups in the presence of clodronate liposomes. In contrast, tumor growth was markedly suppressed by pep-20 compared with normal saline group in the presence of control liposomes (figure 4B). Overall, these findings indicated that macrophage depletion was able to impair the therapeutic efficacy of pep-20.

To further verify whether depletion of macrophages could attenuate the effects of pep-20 on antitumor immune response, the activity of $\mathrm{CD} 8^{+} \mathrm{T}$ cells after clodronate liposomes treatment was studied. When the macrophages were depleted, a significant reduction in the percentages of intratumoral $\mathrm{CD}^{+} \mathrm{T}$ cells was observed with pep-20 treatment, compared with the mice without macrophages depletion (figure 4C). Additionally, the IFN- $\gamma$-expressing $\mathrm{CD}^{+} \mathrm{T}$ cells from the draining lymph nodes and spleen following stimulation with PMA and ionomycin ex vivo were examined. The secretion of IFN- $\gamma$ from $\mathrm{CD}^{+} \mathrm{T}$ cells showed no significant differences with or without pep-20 treatment after macrophages depletion despite the increase of $\mathrm{CD}^{+} \mathrm{T}$ cells population in the tumor tissue, indicating the critical role of macrophages in mediating the antigen cross-presentation and 
A.

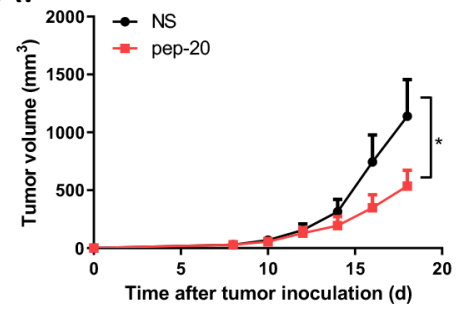

C.

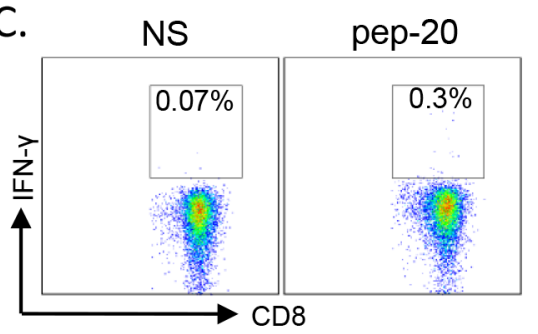

B.
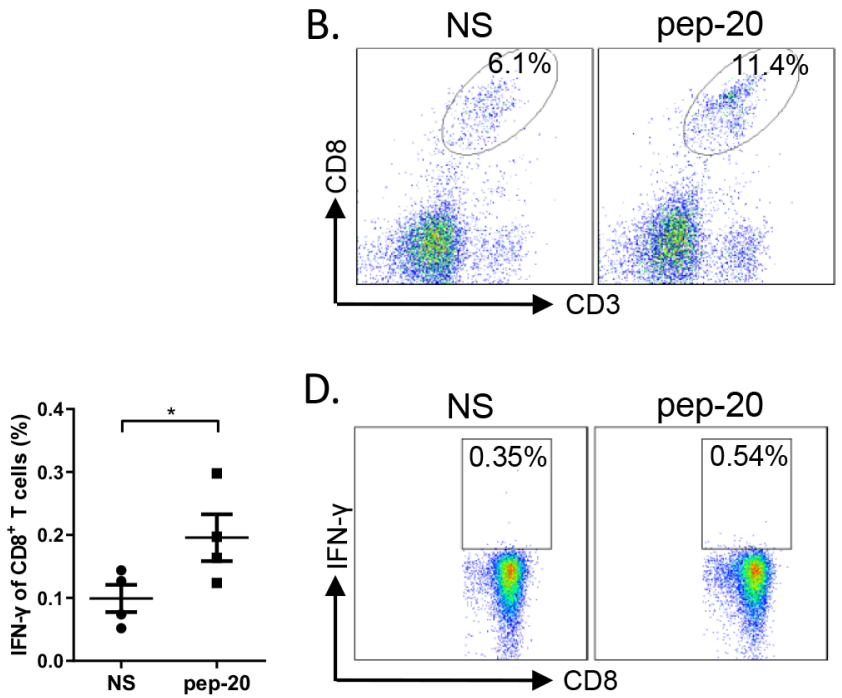

D.

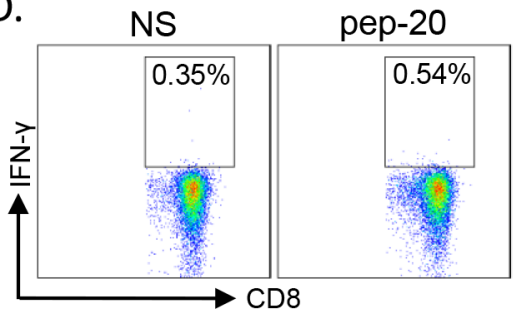

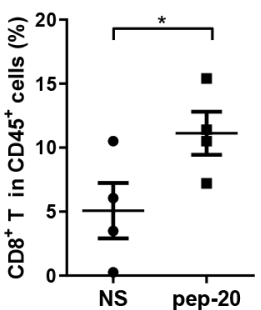

NS pep-20

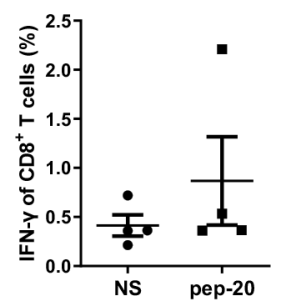

E.

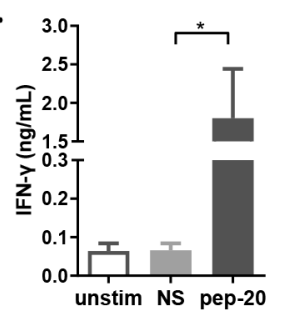

F.

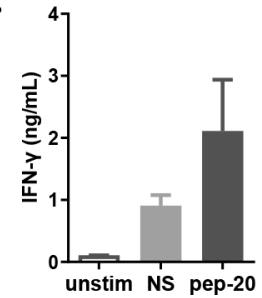

Figure 3 Pep-20 inhibits tumor growth and activates specific antitumor T-cell immune response in B16-OVA tumor-bearing mice. C57BL/6 mice were injected with $2 \times 10^{5} \mathrm{~B} 16-\mathrm{OVA}$ cells on the right flank until the tumor volume reached $30 \mathrm{~mm}^{3}$. (A) Mice were treated s.c. with $2 \mathrm{mg} / \mathrm{kg}$ of pep-20 or normal saline as the negative control at the peritumoral site every day for 2 weeks ( $n=5$ to 6). (B) Tumors were detected for the percentage of tumor-infiltrating CD8 $8^{+}$cells in total $C D 45^{+}$cells $(n=4)$. (C, D) Cells from draining lymph nodes (C) or spleens (D) were obtained and stimulated with $10 \mu \mathrm{g} / \mathrm{mL}$ of $\mathrm{OVA}_{257-264}$ peptide containing protein transport inhibitor cocktail for 6 hours. Frequencies of IFN- $\gamma$ expressing $C D 8^{+} T$ cells were detected by flow cytometry $(n=4)$. (E, F) Cells from draining lymph nodes (E) or spleens (F) were obtained and stimulated with $10 \mu \mathrm{g} / \mathrm{mL}$ of OVA ${ }_{257-264}$ peptide for 5 days. Cellular supernatant from draining lymph nodes and spleen for IFN- $\gamma$ secretion was measured with ELISA assay $(n=4)$. Data are represented as means \pm SEM. Statistical significance was determined by unpaired Student's $t$-test. ${ }^{\star} p<0.05$; ${ }^{* *} \mathrm{p}<0.01$. IFN, interferon.

thus activating the $\mathrm{CD} 8^{+} \mathrm{T}$ cells (figure $4 \mathrm{C}-\mathrm{E}$ ). Therefore, these results indicated that the antitumor effects of pep-20 were dependent on $\mathrm{CD}^{+}$T-cell activation mediated by macrophages.

\section{Pep-20 displays no significant toxicity in mice}

Previous studies have demonstrated that CD47 is expressed on a variety of cells, including hematopoietic cells. ${ }^{6}$ Therefore, the blood toxicity caused by CD47/ SIRP $\alpha$ blockade has received more attention. To preliminarily assess the toxicity of pep-20 in vivo, C57BL/6 naive mice were injected s.c. with pep-20 at a dose of $2 \mathrm{mg} /$ $\mathrm{kg}$ daily over 14 days. Blood samples were collected, and hematological parameters were analyzed either before or after pep-20 treatment. It was found that the red blood cell count and hemoglobin level had no significant differences (online supplemental figure S10A,B). Subsequently, the organ coefficients and hepatic damage analysis also revealed no significant differences after pep-20 treatment (online supplemental table S2 and S3). Consistently, histopathology analysis illustrated no abnormalities by H\&E staining of tissue sections from major organs (online supplemental figure S10C). Collectively, the results demonstrated that pep-20 could not induce anemia and other obvious side effects at a dose of $2 \mathrm{mg} /$ $\mathrm{kg}$ in mice.

\section{Prediction of docking model of pep-20 to CD47}

To determine the binding detail of pep-20 to CD47, the 3D conformation of pep-20 was predicted by PEP-FOLD3, as shown by using the MOE software (online supplemental figure S11A). Next, the possible interaction of pep-20 with human CD47 protein (PDB ID: 2JJS) ${ }^{27}$ was predicted by ZDOCK. In order to confirm the binding model, pep-20derived alanine substitution analogs were tested by cellbased blocking assay. As shown in online supplemental figure $\mathrm{S} 11 \mathrm{~B}$, the predicted $\mathrm{W} 2$, W6, Y9 and W10 residues may be the major binding sites. Subsequently, a possible binding pattern complex 796 was obtained by correlation analysis of the top 1000 predictions (online supplemental figure $\mathrm{S} 11 \mathrm{C}$ ), and the docking model and interaction residues of $\mathrm{CD} 47$ / pep-20 were displayed (online supplemental figure S11A). It was found that the binding sites of CD47/pep-20 were located exactly within the CD47/ 
A.

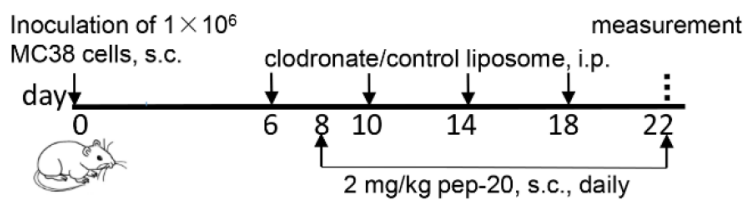

B.

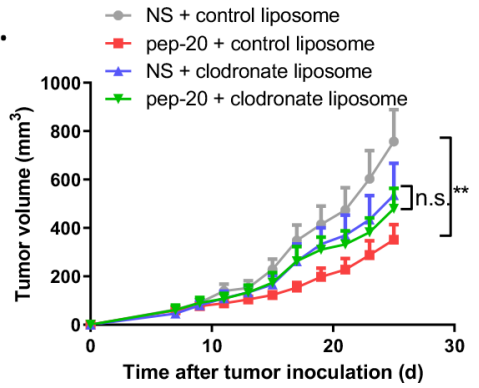

C.
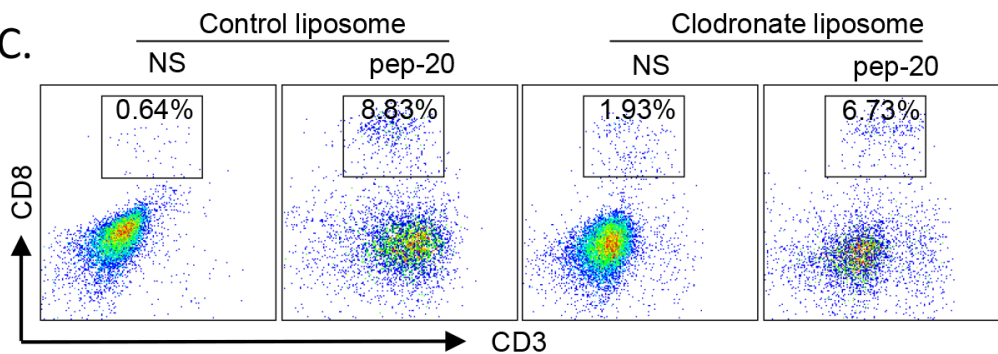

D.
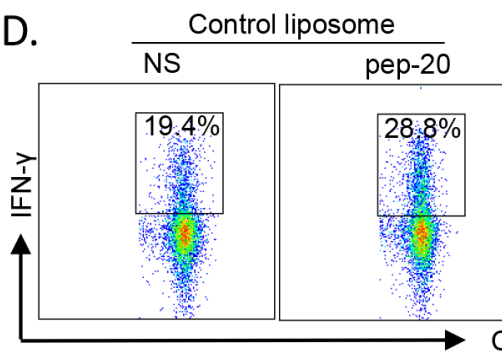

$\mathrm{CD} 8$

E.

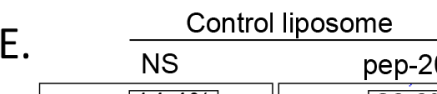
\begin{tabular}{l}
\multicolumn{2}{c}{ Control liposome } \\
NS \\
pep-20 \\
\hline $4.4 \%$
\end{tabular}

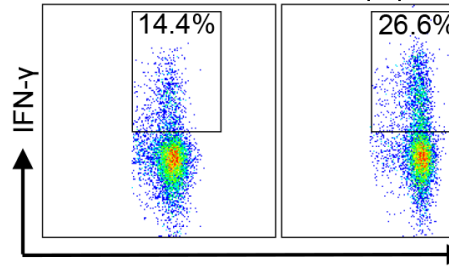

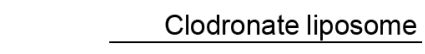

Clodronate liposome

Clodronate liposome

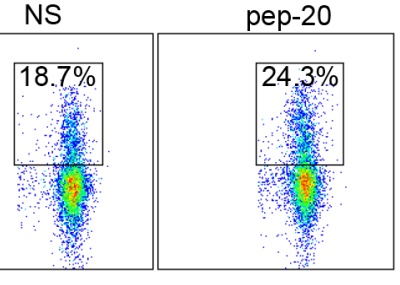

Clodronate liposome

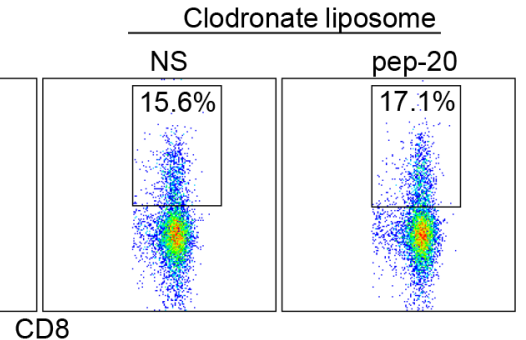

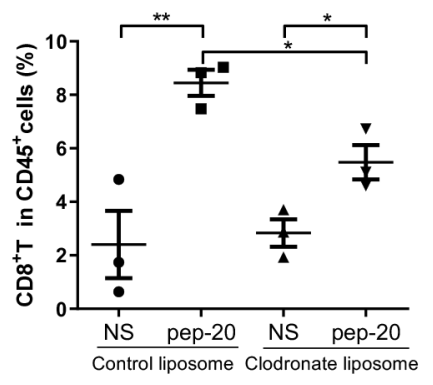
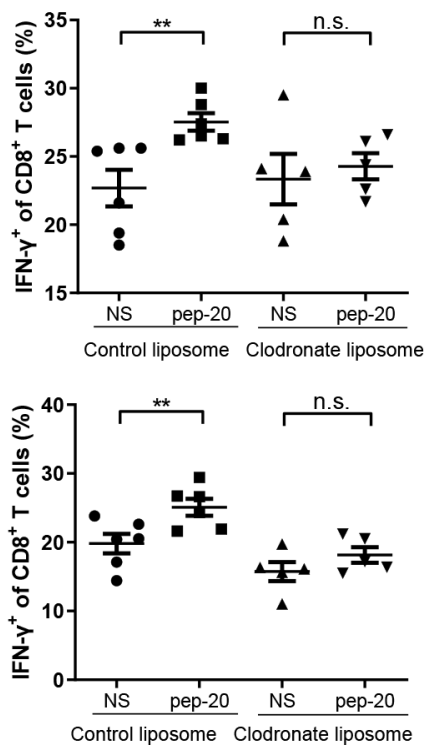

Figure 4 Depletion of macrophages impairs the antitumor efficacy of pep-20 in vivo. C57BL/6 mice were transplanted with $1 \times 10^{6} \mathrm{MC} 38$ cells on the right flank, until the tumor volume reached $50 \mathrm{~mm}^{3}$. (A, B) Mice were treated s.c. with $2 \mathrm{mg} / \mathrm{kg}$ of pep-20 or normal saline as the negative control at the peritumoral site every day, starting on day 8 for 2 weeks and $150 \mu \mathrm{L}$ clodronate liposomes or control liposomes were injected i.p. on days 6, 10, 14 and 18. ( $n=5$ to 6). (C) Tumors were detected for the percentage of tumor-infiltrating CD8 ${ }^{+} T$ cells in total CD45 cells $(n=3)$. (D, E) Cells from draining lymph nodes (D) and spleens (E) were obtained and stimulated with $20 \mathrm{ng} / \mathrm{mL}$ of PMA and $1 \mu \mathrm{M}$ ionomycin-containing protein transport inhibitor cocktail for 4 hours. Frequencies of IFN- $\gamma$-expressing $C D 8^{+} T$ cells were detected by flow cytometry $(n=5$ to 6$)$. Data are represented as means \pm SEM. Statistical significance was determined by unpaired Student's t-test. ${ }^{*} p<0.05,{ }^{* *} p<0.01$. IFN, interferon; i.p. intraperitoneally; n.s., no significance; PMA, phorbol 12-myristate 13-acetate; s.c., subcutaneously.

SIRP $\alpha$ interaction interface (online supplemental figure S11D). These findings revealed the docking model of pep-20, which lays down a potential platform to generate more potent derivates in the future.

\section{Pep-20-D12 blocks the CD47/SIRP $\alpha$ interaction and enhances proteolysis stability compared with parent pep-20}

To develop a more stable peptide which could be administered systemically, modification of pep-20 with D-amino acid substitution was attempted. According to the docking model on the interaction of pep-20 and CD47, and to ensure the blockading effect and hydrolysis stability, both
N-terminal and C-terminal residues were systematically substituted by up to three D-amino acids (online supplemental table S4). The blocking assay was performed as mentioned above. The results showed that pep-20-D12, with three D-amino acid residues substituted both in $\mathrm{N}$-terminal and C-terminal of the parent pep-20, could retain the blockade activity toward human and mouse $\mathrm{CD} 47 / \mathrm{SIRP} \alpha$ (online supplemental figure S12A,B), indicating that the $\mathrm{N}$-terminal and C-terminal residues of pep-20 could be substituted without significant functional decrease. Subsequently, the enzymatic degradation 
stability was examined in $10 \%$ human serum at $37^{\circ} \mathrm{C}$. Different from parent pep-20, pep-20-D12 exhibited potent proteolytic resistance, which retained the same initial concentration for up to 36 hours (online supplemental figure S12C,D). In addition, pep-20-D12 showed more prolonged half-life $\left(\mathrm{T}_{1 / 2}\right)$ in vivo with the intravenous elimination $\mathrm{T}_{1 / 2}$ of 6.36 hours and $\mathrm{C}_{\max }$ of $54.45 \mu \mathrm{g} /$ $\mathrm{mL}(40 \mathrm{mg} / \mathrm{kg})$ in C57BL/ 6 mice than pep-20 with $\mathrm{T}_{1 / 2}$ of 0.59 hours and $\mathrm{C}_{\max }$ of $33.60 \mu \mathrm{g} / \mathrm{mL}$ (online supplemental figure $\mathrm{S} 12 \mathrm{E}, \mathrm{F}$ ). These findings suggested that the stability of pep-20 could be greatly improved by terminal D-amino acid substitution.

\section{Pep-20-D12 inhibits the growth of tumors and activates antitumor T-cell immune response via systemic administration}

In view of the evidence that pep-20-D12 has better proteolytic stability than parent pep-20, the antitumor efficacy and immune stimulatory activity of both peptides were performed in MC38-bearing mice via systemic treatment. Pep-20-D12 slowed the tumor progression significantly, whereas pep-20 had a slight impact on tumor growth (online supplemental figure S13A). Similarly, pep-20-D12 enhanced the infiltration of tumor-specific $\mathrm{T}$ cells and antitumor immunity (online supplemental figure S13B-D).

Consistently, the tumor growth inhibition efficacy by systemic treatment of pep-20-D12 was similar as the antiCD47 antibody (figure 5A,B). To examine the effects of pep-20-D12 treatment on antitumor T-cell immune response, $\mathrm{CD}^{+} \mathrm{T}$ cells from tumor tissues, tumor-draining lymph nodes and spleen were analyzed. Blockade of CD47 with systemically pep-20-D12 treatment also remarkably increased the $\mathrm{CD} 8^{+} \mathrm{T}$ cell population in tumor tissues (figure $5 \mathrm{C}$ ). Furthermore, IFN- $\gamma$ production by $\mathrm{CD} 8^{+} \mathrm{T}$ cells from TILs, tumor-draining lymph nodes and spleen was also significantly increased, especially in TILs and draining lymph nodes (figure 5D-F). More importantly, pep-20-D12 showed less blood toxicity compared with anti-CD47 antibody by evaluating the hematological parameters of mice after treatment (online supplemental figure S14A,B). These results indicated that pep-20-D12 maximally extended antitumor effects with systemic administration.

\section{Combination of pep-20-D12 with irradiation synergistically inhibits tumor growth}

It was reported that the proportion of monocytic myeloidderived suppressor cells (M-MDSCs) in tumor tissues increased significantly after local IR in mice. ${ }^{28}$ Considering that these cells could be differentiated into macrophages subsequently, ${ }^{2930}$ we attempted to evaluate whether combined pep-20-D12 treatment with IR could be more effective to inhibit tumor growth than either treatment alone. MC38 tumors locally received IR once (20 Gy) and were then treated by injection i.p. of pep-20-D12 daily for 2 weeks. Surprisingly, a combination of pep-20-D12 treatment with IR showed a significant delay or even complete regression in tumor growth (figure 6A,B). The mechanism study indicated that the proportion of tumor infiltrating macrophages and monocyte-derived MDSCs was significantly increased on day 3 and the end of treatment by IR (online supplemental figure S15A,B, figure 6C-F) . More importantly, pep-20-D12 could promote the tumor infiltrating monocyte-derived MDSCs-mediated phagocytosis of tumor cells (online supplemental figure S15C). These results demonstrated that the combination of CD47 blockade pep-20-D12 peptide with IR could be a very promising strategy to synergistically eradicate the tumor.

\section{DISCUSSION}

CD47, as a ubiquitous cell-surface inhibitory receptor, interacts with SIRP $\alpha$ on phagocytic cells to deliver inhibitory signals, thus inhibiting the phagocytosis and evading immune surveillance. Recent preclinical or clinical studies suggested that the strategies of blocking anti-phagocytic CD47/SIRP $\alpha$ interaction to enable macrophages phagocytosis of tumor cells showed promise in cancer therapy. ${ }^{31}{ }^{32}$ Here, our results provided the evidence about the overexpression of CD47 in human colorectal tumor tissues compared with the matched normal tissues, and the increased CD47 expression negatively correlated with overall survival, which indicated poor clinical outcomes. Based on these results, a CD47-targeting peptide, pep-20, was identified to specifically bind to human CD47-IgVDomain and block the CD47/SIRP $\alpha$ interaction. Western blotting results revealed that pep-20 directly disturbed the CD47/SIRP $\alpha$ interaction by inhibiting SIRP $\alpha$ tyrosine phosphorylation of ITIMs in cytoplasmic domain.

Surprisingly, pep-20 could bind to human or mouse CD47 in a dose-dependent manner as well as elicit blockade effects. The sequence identity of human and mouse CD47 is $76 \%$. It was also found the sequences of natural receptor-ligand interaction regions determined by crystal structure analysis exihibited a higher overlap. ${ }^{27}$ The binding regions in which pep-20 interact with CD47 might be highly consistent between human and mouse. Blocking assays of pep-20-derived alanine substitution analog peptides were performed to verify the major contact residues. The predicted binding sites of pep-20 to $\mathrm{CD} 47$ were presented in the interaction regions of natural CD47/SIRP $\alpha$ obtained by crystal structure analysis, indicating pep-20 could directly block their interaction. Above all, the docking model can be exploited for performing various studies, such as structural simulation and molecular docking, which could provide the binding detail of peptides interact with receptors, and thus provide more relevant information for the optimization of peptides in the future. ${ }^{33}$

Moreover, the results indicated that pep-20 could act as a blocker to enable engulfment of tumor cells by macrophages in vitro and in vivo. Blockade effects of disrupting the $\mathrm{CD} 47 / \mathrm{SIRP} \alpha$ interaction elicit direct macrophagesmediated phagocytosis rather than antibody-dependent 
A.

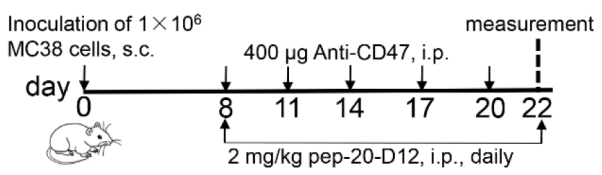

B.

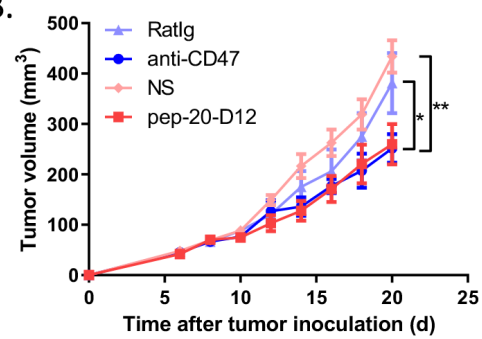

C.
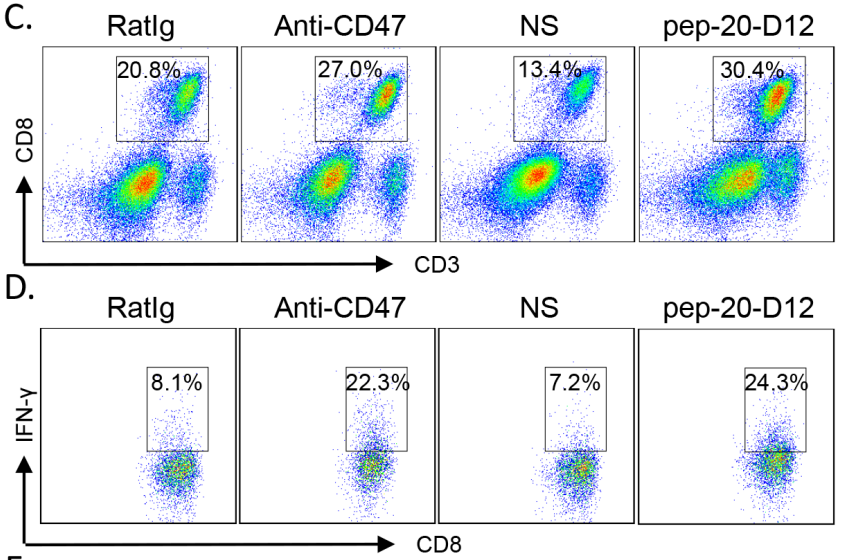

E.

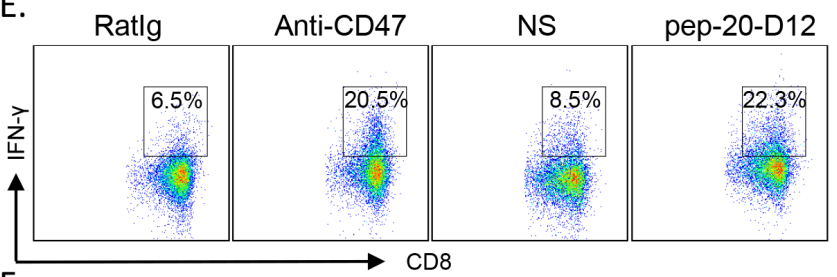

F.

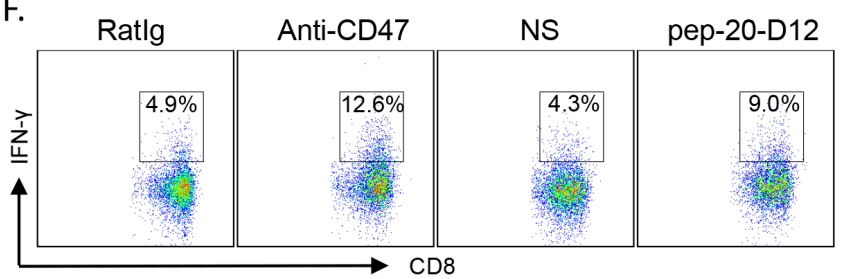

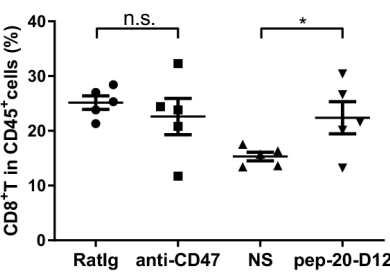
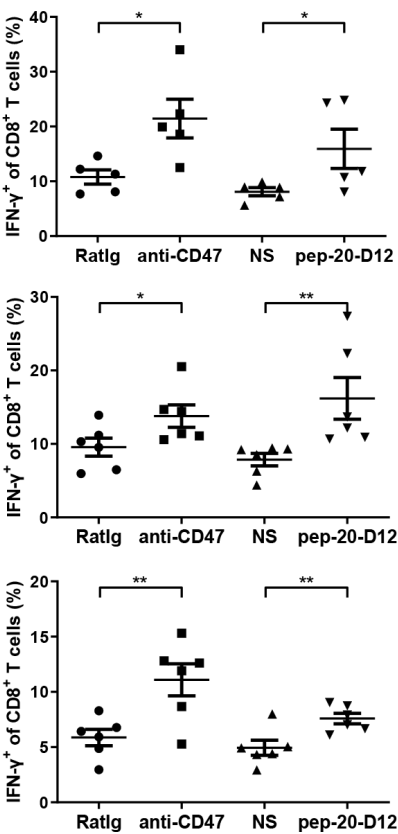

Figure 5 Pep-20-D12 inhibits the growth of tumors and activates antitumor T-cell immune response via systemic administration. C57BL/6 mice were transplanted with $1 \times 10^{6} \mathrm{MC} 38$ cells on the right flank, until the tumor volume reached 50 $\mathrm{mm}^{3}$. (A, B) Mice were treated i.p. with $2 \mathrm{mg} / \mathrm{kg}$ of pep-20-D12 every day for 2 weeks or $400 \mathrm{\mu g}$ of anti-mouse CD47 antibody (miap301) every 3 days for a total of five times as the positive control, and normal saline and Ratlg as the negative controls $(n=8)$. (C) Tumors were detected for the percentage of tumor-infiltrating CD8 ${ }^{+} T$ cells in total $C D 45^{+}$cells $(n=5)$. ( $D$ to $\left.F\right)$ Cells from tumor-infiltrating lymphocytes (D), draining lymph nodes $(E)$ or spleens (F) were obtained and stimulated with $20 \mathrm{ng} / \mathrm{mL}$ of PMA and $1 \mu \mathrm{M}$ ionomycin-containing protein transport inhibitor cocktail for 4 hours. IFN- $\gamma$-expressing $C D 8^{+} \mathrm{T}$ cells were detected by flow cytometry. $(n=5)$. Data are represented as means \pm SEM. Statistical significance was determined by unpaired Student's t-test. " $p<0.05$; ${ }^{* *} p<0.01$. IFN, interferon; i.p. intraperitoneally; n.s., no significance; PMA, phorbol12-myristate 13-acetate; s.c., subcutaneously.

cell-mediated cytotoxicity (ADCC) or other mechanisms to disrupting the interaction. Due to the ubiquitous expression of $\mathrm{CD} 47$ on various cells, including erythrocytes and platelets, in addition to high expression on tumor cells, the side effects of hematological toxicity caused by non-specific clearance has been a major drawback for CD47 targeting cancer therapy, which may restrict the clinical applications of $\mathrm{CD} 47$ blockade. Therefore, the agents targeting CD47 have shown some disadvantages, including the trouble in determining the administered doses to avoid the side effects as well as the low bioavailability caused by disordered binding and clearance of erythrocytes in vivo. ${ }^{34} 35$ To overcome this, many strategies have been attempted to simply block antiphagocytic signals using single-chain variable fragment, the IgG4 isotype Fc region instead of IgG1 or other molecules which are not dependent on the ADCC activity. ${ }^{36}$ In the present study, C57BL/6 mice received pep-20 and its D-amino acid derivate treatment showed no significant adverse effects such as anemia, liver and kidney damage. Thus, it can be speculated that the peptides absenting functional IgG1 Fc regions are not able to trigger FcRmediated ADCC and complement-dependent cytotoxicity effects. 
A.

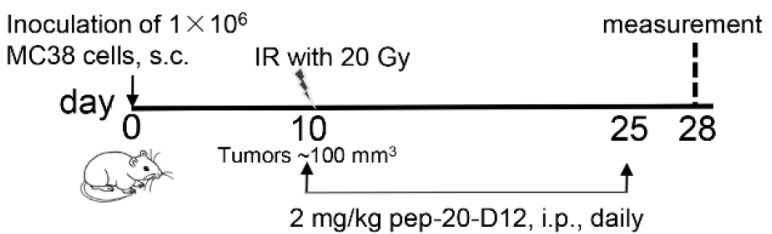

B.

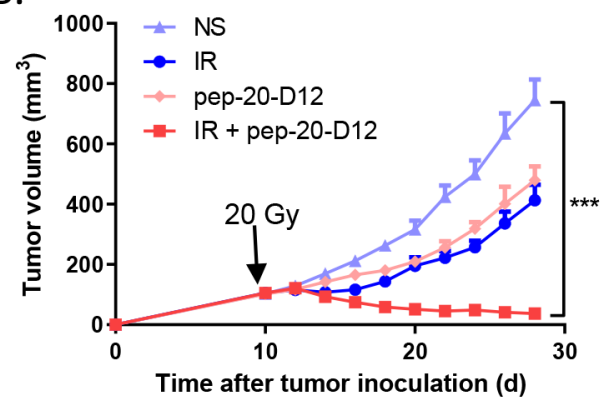

C.

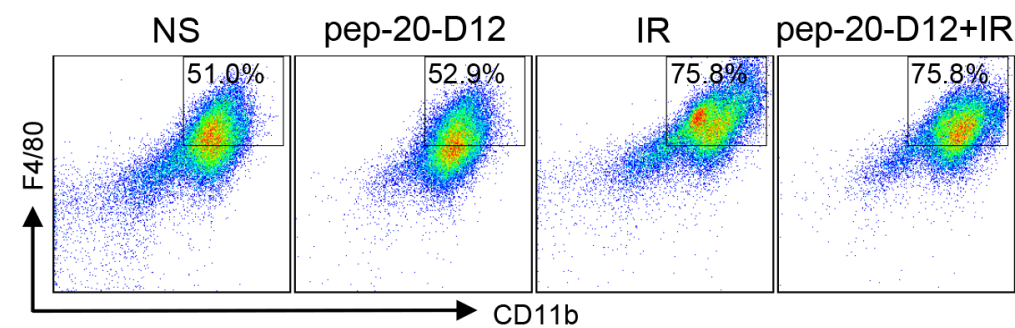

E.

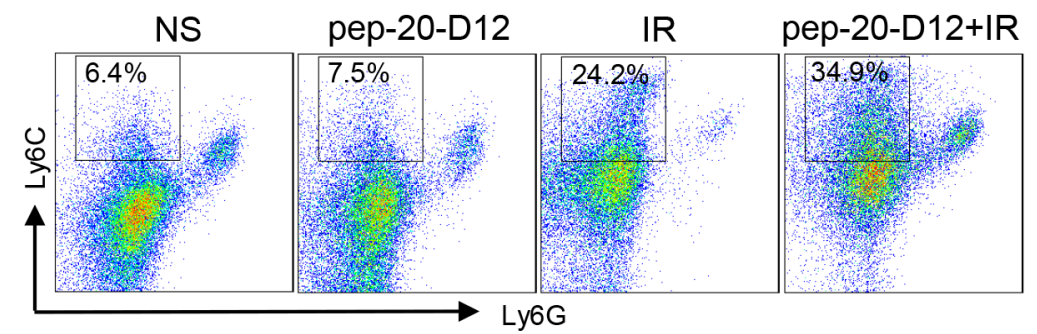

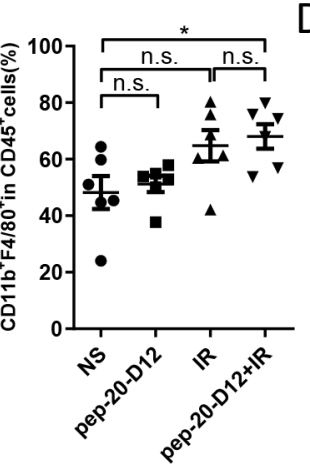

D.
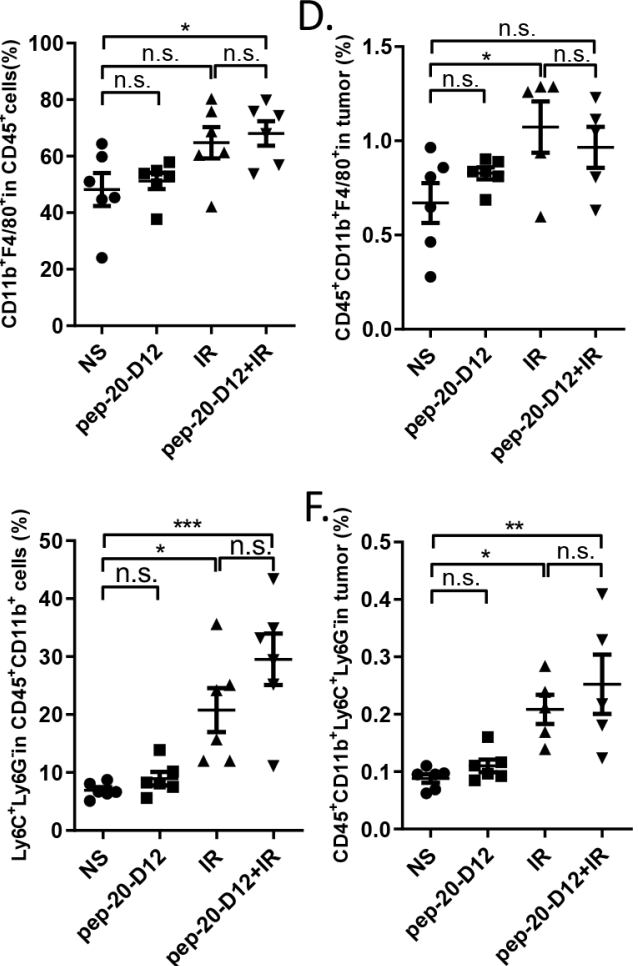

Figure 6 Combination of pep-20-D12 treatment with IR synergistically delays tumor growth. C57BL/6 mice were transplanted with $1 \times 10^{6}$ MC38 cells on the right flank, and tumors were allowed to grow to $\sim 100 \mathrm{~mm}^{3}$ before treatment with IR. (A, B) Tumors locally received one 20 Gy dose IR, and $2 \mathrm{mg} / \mathrm{kg}$ of pep-20-D12 was daily i.p. injected from the same day of IR for 2 weeks. Tumor growth was monitored after IR ( $n=7)$. (C, F) Infiltrating immune cell subsets in tumors were analyzed after treatment. The percentages of intratumoral macrophages $\left(C D 45^{+} \mathrm{CD} 11 \mathrm{~b}^{+} \mathrm{F} 480^{+}\right)(\mathrm{C}, \mathrm{D})$ and monocyte-derived MDSCs $\left(C D 45^{+} C D 11 b^{+} L_{6 C} C^{+}\right.$Ly6G) $(E, F)$ in total tumor tissues were evaluated by flow cytometry ( $n=5$ to 6$)$. Data are represented as means \pm SEM, Statistical significance was determined by one way analysis of variance. ${ }^{\star} p<0.05 ;{ }^{* *} p<0.01 ;{ }^{* * *} p<0.001$. i.p.intraperitoneally; IR, irradiation; MDSC, myeloid-derived suppressor cells; n.s., no significance; s.c., subcutaneously.

Peptide treatments can activate macrophages-mediated phagocytosis through direct blockade effects which weaken the off-target clearance of erythrocytes. Moreover, Advani et al proposed that CD47 blockade with a low dose at the beginning, followed by a higher grade maintenance dose, minimized the side effects of anemia. ${ }^{32}$ Our work was partly consistent with this strategy. Compared with antibodies and fusion proteins, the $\mathrm{T}_{1 / 2}$ of peptides is relatively short, which may weaken the therapeutic effect to some extent. In return, adverse effects could be managed timely and effectively for clinical treatments. Furthermore, administering a large dose of inhibitors in a short period may break the balance of pro-phagocytic and antiphagocytic signals which are partly regulated by cellular homeostasis, even normal cells are not subjected to phagocytosis because of lack of pro-phagocytic signaling. ${ }^{38}$ In response to erythrocyte decline, peptide treatment may be a relatively milder strategy that enables maintaining relative homeostasis or returning to a stable state after a short period of disequilibrium via a compensatory effect. While macrophages are the main effector cells of CD47/ SIRP $\alpha$ pathway from current studies, it is undeniable that the presence of $\mathrm{Fc}$ receptor (FcR)-mediated ADCC and antibody-dependent cellular phagocytosis (ADCP) effectively synergize antitumor therapy by phagocytes, even the contradictory relationship between antitumor effects and potential side effects can be balanced. ${ }^{39}$ Therefore, agents of CD47/SIRP $\alpha$ blockade for enhancement of 
phagocytosis function by blocking 'don't eat me' signals combined with cancer-targeting therapeutic antibodies, FcR-mediated ADCC and ADCP, may be a more effective approach to potently eliminate tumors at the current stage. ${ }^{12} 3440$

Previous studies have provided evidence that macrophages could effectively phagocytose tumor cells, and dendritic cells (DCs) could elicit increased activation of $\mathrm{T}$ cells in the tumor microenvironment after anti-CD47 therapy. Since DCs and macrophages are important components of innate immune system for phagocytosis and antigen presentation which can bridge innate and adaptive immunity, it is possible that they are synergistic to the removal of tumor cells, and to stimulate $\mathrm{CD} 8^{+} \mathrm{T}$ cells and initiate antitumor T-cell immune response. ${ }^{414}$ In the present study, the pep-20-mediated phagocytosis of tumors by macrophages initiated antitumor T-cell immune response with a marked increase of $\mathrm{CD}^{+} \mathrm{T}$ cells in tumor tissues, and the IFN- $\gamma$-secreting $\mathrm{CD}^{+} \mathrm{T}$ cells were significantly amplified. ${ }^{43}$ Macrophages engulfed OVA-expressing tumor cells and presented antigen, thus effectively activating OT-IT cell proliferation and secretion of IFN- $\gamma$ cytokines in the presence of pep-20. In addition, removal of macrophages invalidated the therapeutic effects of pep-20 and impaired the activation of $\mathrm{CD}^{+} \mathrm{T}$ cells in tumor-bearing mice. Collectively, these results suggested that pep-20 depended on macrophages to exert antitumor effects and participated in motivating antitumor immune response.

A variety of therapeutic peptides and derivative drugs have been approved by the Food and Drug Administration for diverse disease diagnosis and treatments. ${ }^{44}$ Despite the limitations in wide applications of peptide drugs, such as low solubility, relatively short circulating $\mathrm{T}_{1 / 2}$, poor stability and limited oral bioavailability, many strategies including cyclization, PEGylation modifications, adjunction of D-amino acids and conjugation with serum albumin have been utilized to refine the peptide drugs. ${ }^{45-47}$ Retro-inverso peptide ensures the stability of proteases which possess similar side-chain topologies and biological activities to interact with its receptor. However, pep-20 containing $\alpha$-helices structure may not maintain the same biological activity as parent L-peptides to the retro-inverso isomerization due to the change at the secondary structure. ${ }^{48} \mathrm{D}$-amino acid substitutions at the $\mathrm{N}$-terminal and C-terminal of the peptide which showed little effect on the $\alpha$-helical structure were adopted to circumvent these problems. ${ }^{49}$ Pep-20-D12 containing D-amino acid substitutions at the N-terminal and C-terminal proved to be highly stable to enzymatic degradation and effectively maintain blocking activity.

RT results in inducing tumor cell death and triggers antitumor immune response, but in most cases, the response is insufficient to maintain, and relapses always occur. ${ }^{28}$ The combination of pep-20-D12 with IR treatment exerted more effectiveness in synergistically delaying tumor growth than IR alone, especially suppressing relapses.
The effect of combining CD47 blockade with IR may be ascribed to multiple mechanisms. It is well accepted that IR can induce immunogenic cell death, resulting in prophagocytic signals exposure to the tumor cell membrane (calreticulin, phosphatidylserine and so on), which may be very conducive to enhancing macrophage-dependent phagocytosis of CD47 blockade. Moreover, our results showed that local IR leads to significant increase of intratumoral macrophages $\left(\mathrm{CD} 11 \mathrm{~b}^{+} \mathrm{F} 480^{+}\right)$and monocytic MDSCs $\left(\mathrm{CD}_{11} \mathrm{~b}^{+} \mathrm{Ly} 6 \mathrm{C}^{+} \mathrm{Ly}_{6 \mathrm{G}^{-}}\right)$which may differentiate into macrophages or directly participate in the phagocytosis of tumor cells. ${ }^{50}$

\section{CONCLUSION}

In conclusion, a novel pep-20 peptide was identified by phage display bio-panning, which could markedly interfere the CD47/SIRP $\alpha$ interaction, enhance macrophagemediated phagocytosis and elicit antitumor effects. The proteolysis-resistant analog pep-20-D12 could serve as a potential candidate for cancer immunotherapy by blocking CD47/SIRP $\alpha$, especially in combination with RT to elicit synergistic effects.

Acknowledgements We would like to thank Xuanming Yang, Xiaojuan Liu and Shengdian Wang for providing the mice, cell lines and anti-CD47 antibody.

Contributors YG and HW conceived the research and designed the experiments. HW performed the majority of experiments, acquired and analyzed the data with critical support from YS, XZ, JD, CC, WL, SG, LJ and YL. All the authors contributed to provide samples, write and review the manuscript.

Funding This work was supported by grants from the National Natural Science Foundation of China (Nos. 81822043, U1604286), the Key Incubation Fund of SYSU (19ykzd29), and "Pearl River Talent Plan" Innovation and Entrepreneurship Team Project of Guangdong Province (2019ZT08Y464).

Competing interests None declared.

Patient consent for publication Not required.

Ethics approval All animal experiments were performed in accordance to the animal experimental guidelines and approved by the Ethics Committee of Zhengzhou University.

Provenance and peer review Not commissioned; externally peer reviewed.

Data availability statement Data are available in a public, open access repository. All data relevant to the study are included in the article or uploaded as supplementary information. The data sets generated and/or analyzed during the current study are available from the corresponding author on reasonable request.

Open access This is an open access article distributed in accordance with the Creative Commons Attribution 4.0 Unported (CC BY 4.0) license, which permits others to copy, redistribute, remix, transform and build upon this work for any purpose, provided the original work is properly cited, a link to the licence is given, and indication of whether changes were made. See https://creativecommons.org/ licenses/by/4.0/.

\section{ORCID iDs}

Xiuman Zhou http://orcid.org/0000-0002-5938-450X

Yanfeng Gao http://orcid.org/0000-0001-5533-7100

\section{REFERENCES}

1 Gordon S, Plüddemann A, Martinez Estrada F. Macrophage heterogeneity in tissues: phenotypic diversity and functions. Immunol Rev 2014;262:36-55.

2 Arandjelovic S, Ravichandran KS. Phagocytosis of apoptotic cells in homeostasis. Nat Immunol 2015;16:907-17. 
3 Brown GC, Neher JJ. Microglial phagocytosis of live neurons. Nat Rev Neurosci 2014;15:209-16.

4 Barclay AN, Van den Berg TK. The interaction between signal regulatory protein alpha (SIRP $\alpha$ ) and CD47: structure, function, and therapeutic target. Annu Rev Immunol 2014;32:25-50.

5 Jaiswal S, Jamieson CHM, Pang WW, et al. Cd47 is upregulated on circulating hematopoietic stem cells and leukemia cells to avoid phagocytosis. Cell 2009;138:271-85.

6 Oldenborg PA, Zheleznyak A, Fang YF, et al. Role of CD47 as a marker of self on red blood cells. Science 2000;288:2051-4.

7 Wang H, Madariaga ML, Wang S, et al. Lack of CD47 on nonhematopoietic cells induces split macrophage tolerance to CD47null cells. Proc Natl Acad Sci U S A 2007:104:13744-9.

8 Willingham SB, Volkmer J-P, Gentles AJ, et al. The CD47-signal regulatory protein alpha (SIRPa) interaction is a therapeutic target for human solid tumors. Proc Natl Acad Sci U S A 2012;109:6662-7.

9 Weiskopf K, Ring AM, Ho CCM, et al. Engineered SIRP $\alpha$ variants as immunotherapeutic adjuvants to anticancer antibodies. Science 2013;341:88-91.

10 Ho CCM, Guo N, Sockolosky JT, et al. "Velcro" engineering of high affinity CD47 ectodomain as signal regulatory protein $\alpha(\mathrm{SIRP} \alpha)$ antagonists that enhance antibody-dependent cellular phagocytosis. J Biol Chem 2015;290:12650-63.

11 Majeti R, Chao MP, Alizadeh AA, et al. Cd47 is an adverse prognostic factor and therapeutic antibody target on human acute myeloid leukemia stem cells. Cell 2009;138:286-99.

12 Chao MP, Alizadeh AA, Tang C, et al. Anti-CD47 antibody synergizes with rituximab to promote phagocytosis and eradicate non-Hodgkin lymphoma. Cell 2010;142:699-713.

13 Legrand N, Huntington ND, Nagasawa M, et al. Functional CD47/ signal regulatory protein alpha $(\mathrm{SIRP}($ alpha)) interaction is required for optimal human T- and natural killer- (NK) cell homeostasis in vivo. Proc Natl Acad Sci U S A 2011;108:13224-9.

14 Tseng D, Volkmer J-P, Willingham SB, et al. Anti-CD47 antibodymediated phagocytosis of cancer by macrophages primes an effective antitumor T-cell response. Proc Natl Acad Sci U S A 2013;110:11103-8.

15 Liu X, Pu Y, Cron K, et al. Cd47 blockade triggers T cell-mediated destruction of immunogenic tumors. Nat Med 2015;21:1209-15.

16 Andrechak JC, Dooling LJ, Discher DE. The macrophage checkpoint CD47 : SIRP $\alpha$ for recognition of 'self' cells: from clinical trials of blocking antibodies to mechanobiological fundamentals. Phil. Trans. R. Soc. B 2019;374:20180217.

17 Kaspar AA, Reichert JM. Future directions for peptide therapeutics development. Drug Discov Today 2013;18:807-17.

18 Yan Z, Wu Y, Du J, et al. A novel peptide targeting Clec9a on dendritic cell for cancer immunotherapy. Oncotarget 2016;7:40437-50.

19 Pande J, Szewczyk MM, Grover AK, et al. Innovations, applications and future. Biotechnol Adv 2010;28:849-58.

20 Whitney M, Crisp JL, Olson ES, et al. Parallel in vivo and in vitro selection using phage display identifies protease-dependent tumortargeting peptides. J Biol Chem 2010;285:22532-41.

21 McCracken MN, Cha AC, Weissman IL. Molecular pathways: Activating t cells after cancer cell phagocytosis from blockade of cd47 "don't eat me" signals. Clin Cancer Res 2015;21:3597-601.

22 Cieslewicz M, Tang J, Yu JL, et al. Targeted delivery of proapoptotic peptides to tumor-associated macrophages improves survival. Proc Natl Acad Sci U S A 2013;110:15919-24.

23 Sievers F, Wilm A, Dineen D, et al. Fast, scalable generation of highquality protein multiple sequence alignments using Clustal omega. Mol Syst Biol 2011;7:539.

24 Ide $\mathrm{K}$, Wang $\mathrm{H}$, Tahara $\mathrm{H}$, et al. Role for CD47-SIRPalpha signaling in xenograft rejection by macrophages. Proc Natl Acad Sci U S A 2007;104:5062-6.

25 Matozaki T, Murata $\mathrm{Y}$, Okazawa $\mathrm{H}$, et al. Functions and molecular mechanisms of the CD47-SIRPalpha signalling pathway. Trends Cell Biol 2009;19:72-80.

26 Van Rooijen N, Sanders A. Liposome mediated depletion of macrophages: mechanism of action, preparation of liposomes and applications. J Immunol Methods 1994;174:83-93.
27 Hatherley D, Graham SC, Turner J, et al. Paired receptor specificity explained by structures of signal regulatory proteins alone and complexed with CD47. Mol Cell 2008;31:266-77.

28 Deng L, Liang H, Burnette B, et al. Irradiation and anti-PD-L1 treatment synergistically promote antitumor immunity in mice. J Clin Invest 2014;124:687-95.

29 Gabrilovich DI, Nagaraj S. Myeloid-Derived suppressor cells as regulators of the immune system. Nat Rev Immunol 2009;9:162-74.

30 Bronte V, Brandau S, Chen S-H, et al. Recommendations for myeloid-derived suppressor cell Nomenclature and characterization standards. Nat Commun 2016;7:12150.

31 Kauder SE, Kuo TC, Harrabi O, et al. ALX148 blocks CD47 and enhances innate and adaptive antitumor immunity with a favorable safety profile. PLoS One 2018;13:e0201832.

32 Advani R, Flinn I, Popplewell L, et al. Cd47 blockade by Hu5F9-G4 and rituximab in non-Hodgkin's lymphoma. N Engl J Med 2018;379:1711-21.

33 Kitchen DB, Decornez H, Furr JR, et al. Docking and scoring in virtual screening for drug discovery: methods and applications. Nat Rev Drug Discov 2004;3:935-49.

34 van Bommel PE, He Y, Schepel I, et al. CD20-selective inhibition of CD47-SIRP $\alpha$ "don't eat me" signaling with a bispecific antibody-derivative enhances the anticancer activity of daratumumab, alemtuzumab and obinutuzumab. Oncoimmunology 2018;7:e1386361.

35 Liu B, Guo H, Xu J, et al. Elimination of tumor by CD47/PD-L1 dualtargeting fusion protein that engages innate and adaptive immune responses. MAbs 2018;10:315-24.

36 Sockolosky JT, Dougan M, Ingram JR, et al. Durable antitumor responses to CD47 blockade require adaptive immune stimulation. Proc Natl Acad Sci U S A 2016;113:E2646-54.

37 Liu J, Wang L, Zhao F, et al. Pre-Clinical development of a humanized anti-cd47 antibody with anti-cancer therapeutic potential. PLoS One 2015:10:e0137345

38 Chao MP, Jaiswal S, Weissman-Tsukamoto R, et al. Calreticulin is the dominant pro-phagocytic signal on multiple human cancers and is counterbalanced by CD47. Sci Trans/ Med 2010;2:ra94.

39 Jain S, Van Scoyk A, Morgan EA, et al. Targeted inhibition of CD47$\mathrm{SIRP} \alpha$ requires $\mathrm{Fc}-\mathrm{F} c \gamma \mathrm{R}$ interactions to maximize activity in T-cell lymphomas. Blood 2019;134:1430-40.

40 Zhao XW, van Beek EM, Schornagel K, et al. Cd47-Signal regulatory protein- $\alpha(\operatorname{SIRP} \alpha)$ interactions form a barrier for antibody-mediated tumor cell destruction. Proc Natl Acad Sci U S A 2011;108:18342-7.

41 Liu X, Kwon H, Li Z, et al. Is CD47 an innate immune checkpoint for tumor evasion? J Hematol Oncol 2017;10:12.

42 Feng M, Jiang W, Kim BYS, et al. Phagocytosis checkpoints as new targets for cancer immunotherapy. Nat Rev Cancer 2019;19:568-86.

43 Zhou X-M, Li W-Q, Wu Y-H, et al. Intrinsic Expression of Immune Checkpoint Molecule TIGIT Could Help Tumor Growth in vivo by Suppressing the Function of NK and $\mathrm{CD}^{+} \mathrm{T}$ Cells. Front Immunol 2018;9:2821.

44 Ahrens VM, Bellmann-Sickert K, Beck-Sickinger AG. Peptides and peptide conjugates: therapeutics on the upward path. Future Med Chem 2012;4:1567-86.

45 Fosgerau K, Hoffmann T. Peptide therapeutics: current status and future directions. Drug Discov Today 2015;20:122-8.

46 Chang H-N, Liu B-Y, Qi Y-K, et al. Blocking of the PD-1/PD-L1 interaction by a d-peptide antagonist for cancer immunotherapy. Angew Chem Int Ed Engl 2015;54:11760-4.

47 Zhai W, Zhou X, Wang H, et al. A novel cyclic peptide targeting LAG3 for cancer immunotherapy by activating antigen-specific $\mathrm{CD}^{+} \mathrm{T}$ cell responses. Acta Pharm Sin B 2020;10:1047-60.

$48 \mathrm{Li} \mathrm{C}$, Pazgier M, Li J, et al. Limitations of peptide retro-inverso isomerization in molecular mimicry. J Biol Chem 2010;285:19572-81.

49 Tugyi R, Uray K, Iván D, et al. Partial D-amino acid substitution: improved enzymatic stability and preserved ab recognition of a MUC2 epitope peptide. Proc Natl Acad Sci U S A 2005;102:413-8.

50 Weichselbaum RR, Liang H, Deng L, et al. Radiotherapy and immunotherapy: a beneficial liaison? Nat Rev Clin Oncol 2017;14:365-79. 